\title{
Spatio-temporal variations in unmet need for family planning in Ghana: 2003-2014
}

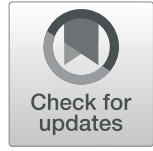

Samuel H. Nyarko*, Corey S. Sparks and Fikrewold Bitew

\author{
* Correspondence: samharrenson@ \\ gmail.com \\ Department of Demography, \\ College of Public Policy, The \\ University of Texas at San Antonio, \\ 501 W. Cesar Chavez Blvd, San \\ Antonio, TX 78207, USA
}

\begin{abstract}
Ghana has long prioritized family planning as a key strategy for improving health and socioeconomic development. However, despite the heavy investments in the sector over the last decade, the family planning program has not successfully improved the country's family planning indicators. In this study, we describe the spatial and temporal patterns of unmet need for family planning from 2003 to 2014 and mainly estimate the socioeconomic factors affecting it. Using data from the 2003, 2008, and 2014 Ghana Demographic and Health Surveys, we map the regional and temporal trends in unmet need for family planning and used Bayesian multilevel logistic regression models to estimate the effects of individual-level socioeconomic characteristics on unmet need for family planning. The results show that there are considerable regional disparities in unmet need for family planning for the study period. These disparities show diverse trends among the ten regions in the country over the study period. The patterns of unmet need for family planning are considerably affected by socioeconomic factors such as educational attainment, household wealth, marital, and work status, as well as age, ethnicity, parity, and time (year). Both socioeconomic and demographic factors play a significant role in the patterns of unmet need for family planning in Ghana. There is the need to formulate consistently effective family planning policies focusing mainly on the higher risk groups of women in the country.
\end{abstract}

Keywords: Spatio-temporal, Unmet need, Family planning, Ghana

\section{Introduction}

Many women of reproductive age in developing countries worldwide are seeking to prevent or postpone pregnancy; however, they are not using any contraceptive methods. These women are considered to have an unmet need for family planning because they are fecund and sexually active and want to avoid or postpone pregnancy but are not using contraception (Sedgh, Ashford, \& Hussain, 2016). Simply put, the concept of unmet need for family planning refers to the gap between women's reproductive intentions and their contraceptive use behavior (WHO, 2019). In the developing countries, between 8 and 38\% of married women aged 15-49 are found to have an unmet need for family planning (Sedgh et al., 2016).

Over the past decade, rising rates of contraceptive use have reduced unmet need for family planning in most developing countries, but the unmet need remains persistently high. This is likely because contraceptive use is much lower in the developing countries (40\%) and is particularly lower in Africa (33\%) (United Nations, 2015). In 
sub-Saharan Africa, the unmet need for family planning was highest (24\%), double the world average in 2015 (United Nations, 2015). However, research has established that reducing the unmet need for family planning by improving upon family planning provides several benefits such as saving the lives of women and children; offering women more choices; and encouraging the adoption of safer sexual behavior. This impacts positively on population growth and helps to protect the environment and aids its development (Upadhyay \& Robey, 1999). Thus, identifying the changes and regional disparities in unmet need for family planning is central for developing effective family planning policies and programs that will help women and couples to choose the number and timing of their children (Guttmacher Institute, 2016).

In spite of the steady decrease in the level of unmet need for family planning worldwide, considerable disparities are still evident among some developing countries (United Nations, 2015). Ghana is, currently, one of the sub-Saharan African countries with high unmet needs for family planning. Since its inception as one of the objectives of the 1969 Ghana Population Policy, the Ghana National Family Planning Programme (GNFPP) has implemented a number of programs such as the contraceptive social marketing program and the family planning and health program. Its main goal was to considerably reduce population growth by providing women the opportunity to decide the number and spacing of their children (Government of Ghana, 1969). With time, emerging issues including adolescent sexual and reproductive health and HIV/AIDS among others have weakened the policy and led to the 1994 Revised Population Policy and Action Plan. In this revised edition, there was a renewed emphasis on ensuring the availability and accessibility of family planning services to all women and on a voluntary basis. It sought to achieve a modern contraception prevalence rate of $28 \%$ by 2010 and 50\% by 2020 (Government of Ghana, 1994). However, GNFPP has seen little success due to myriads of challenges including a dearth of skilled personnel and insufficient government funding among others (Ghana Health Service (GHS), and UNFPA, 2015). Consequently, as part of the Family Planning 2020 (FP2020) agenda set during the 2012 Family Planning Summit in London, UK, the Government of Ghana has made many significant commitments including the need to eliminate user fees for family planning services in all public health facilities and increase demand for family planning among others (Government of Ghana, 2015). It was in this regard that the Ghana Family Planning Costed Implementation Plan, 2016-2020, was developed to facilitate the fulfilment of Ghana's FP2020 commitments and align them with key family planning strategies in 2015 (Government of Ghana, 2015).

Meanwhile, in spite of the substantial investments the sector received over the last decade, Ghana has not been able to record marked and constant improvements in its family planning indicators (Ghana Health Service (GHS), and UNFPA, 2015). It has, therefore, been noted that understanding how desired family size, contraceptive use, and levels of unmet need change over time helps countries to set service priorities in family planning programs (UNFPA, and PATH, 2008). Thus, this study seeks to examine the spatial and temporal patterns of unmet need for family planning in Ghana by answering the following research questions: what are the spatial and temporal patterns of unmet need for family planning in Ghana from 2003 to 2014? Do individual-level socioeconomic factors have a considerable effect on the patterns of unmet need for family planning in Ghana during the study period? The first research question seeks to 
ascertain the disparities in unmet needs among the 10 regions of the country over time and describe the temporal trends of unmet need for family planning during the period. The latter question seeks to estimate the socioeconomic predictors of the observed patterns of unmet need for family planning in the country. Consequently, we hypothesize that women without formal education, women from a poor household, never-married women and unemployed women would have a considerably higher unmet need for family planning even after controlling for demographic characteristics. This is because we believe that these categories of women may be comparatively vulnerable socioeconomically to be able to effectively access and utilize family planning services. This study provides a valuable understanding of the levels of unmet need for family planning across the regions in Ghana over time as well as their associated socioeconomic factors.

\section{Methods}

\section{Data and study population}

This study draws on data from the 2003, 2008, and 2014 waves of the Ghana Demographic and Health Surveys (GDHS). These datasets were merged to allow for temporal trend analysis of the subject while also focusing on regional disparities for each survey year. The GDHS is a nationally representative survey that is conducted as part of the global Demographic and Health Surveys (DHS) program. The survey draws on a twostage sampling design to select samples through an initial selection of clusters and an eventual systematic sampling technique. The 2003 sample comprised 5691 women aged 15-49 that were selected from 6251 households while the 2008 sample includes 4916 women selected from 6141 households (Ghana Statistical Service (GSS), Noguchi Memorial Institute for Medical Research (NMIMR), and ORC Macro, 2004; Ghana Statistical Service (GSS), Ghana Health Service (GHS), and ICF Macro, 2009). The 2014 sample comprised 9396 women selected from 11,835 households nationwide (Ghana Statistical Service (GSS), Ghana Health Service (GHS), and ICF International, 2015). The sample for this study is limited to only sexually active women of reproductive age (married and unmarried). As a result, women who had never had sex and infecund women, as well as women in menopause, were excluded from the study. This is to provide a fair picture of the state of unmet need for family planning in the country over the study period.

\section{Study variables}

The outcome variable is an unmet need for family planning which includes the unmet need for spacing, limiting, spacing failure, and limiting failure as against women who had met the need for family planning. The original definition of unmet need for family planning was used for the 2003 and 2008 surveys whereas the revised version was used for the 2014 survey. The two conceptualizations have been found to produce similar results, even though the revised version has slightly higher results (Bradley, Croft, Fishel, \& Westoff, 2012). The main predictors in this study include socioeconomic factors such as educational level (no education, primary education, secondary/higher), marital status (never married, married/living together, widowed/divorced/separated), work status (working, not working), and household wealth status. In DHS datasets, the wealth status of a household is derived in the form of index from a set of correlated variables 
such as ownership of material possessions including television, radio, car, bicycle, refrigerator, motorcycle, telephone, as well as electricity, quality of roofing and floor material, quality of wall and floor, and source of water through principal components analysis. The wealth index score is divided into quintiles and assigned to the household of each woman to determine whether she is from the poorest, poorer, middle, richer, or richest household. These were grouped into three categories (poor, middle, rich) mainly based on extant literature.

Also, demographic factors such as age (15-19, 20-29, 30-39, 40-49), religious affiliation (Christianity, Islam, traditional, other), ethnicity (Akan, Ga-Dangme, Ewe, Mole-Dagbani, other), parity $(0,1-2,3-4,5+)$, type of residence (urban, rural), and year of survey (2003, 2008, 2014) have been used as control variables in this study. The selection of the study variables was predominantly informed by the extant literature.

\section{Analytic strategy}

The three datasets were merged, and the dependent variable was recoded into a binary outcome (unmet need $=1$, met need $=0$ ). A basic multilevel logistic regression model was fitted for each survey year to generate regional estimates, which were then merged with shapefiles and mapped to present regional disparities. The regional estimates were also extracted and plotted in the form of geometric lines to show the temporal patterns of unmet need for family planning for the study period. Further, the Integrated Nested Laplace Approximations (INLA) approach to Bayesian modeling (Rue, Martino, \& Chopin, 2009), was used to fit three multilevel logistic regression models, using region as the higher hierarchy, in order to estimate the effect of socioeconomic factors unmet need for family planning. The model 1 contains only socioeconomic factors and model 2 controlled for demographic characteristics of respondents while model 3 further controlled for time (survey year) as the full model. The models are summarized in terms of the posterior means of the parameter values, together with the $95 \%$ credible intervals for the parameters. Posterior mean estimates and credible intervals were exponentiated to produce odds ratios and confidence intervals for the odds ratios. All the results were weighted with the complex survey approach to produce an adequate representation of the population of Ghana. The data processing and analysis were done using the $R$ programming language (version 3.5.1) (Core Team, 2018).

\section{Results}

\section{Socio-demographic characteristics of respondents}

Descriptive results on the background characteristics of the respondents and the prevalence of unmet need for family planning have been presented in Table 1 for each of the survey years as well as all the years combined. On the whole, the large proportion of the respondents comprised women aged 20-29(39.9\%) and 30-39(36.0\%) while more than half of the respondents had secondary school or higher education (53.9\%) whereas $26.4 \%$ had no formal education. Also, the majority of the respondents were affiliated with the Christian religion (83.3\%) and more than half were Akans (51.5\%). With regard to wealth, more than one-third of the respondents were from poor households (36.9\%) whereas 43.3\% were from rich households. The majority of the respondents were either married or living together with their partners $(84.2 \%)$ while the majority were also working $(83.1 \%)$ at 
Table 1 Socio-demographic characteristics and prevalence of unmet need: 2003-2014

\begin{tabular}{|c|c|c|c|c|}
\hline Characteristics & 2003 & 2008 & 2014 & All years \\
\hline Age & $\%$ & $\%$ & $\%$ & $\%$ \\
\hline $15-19$ & $20.2(45.4)$ & $20.8(45.7)$ & $17.3(43.4)$ & $6.6(44.7)$ \\
\hline $20-29$ & $34.5(36.8)$ & $34.8(39.2)$ & $34.2(29.7)$ & $39.9(34.2)$ \\
\hline $30-39$ & $26.8(35.0)$ & $26.1(36.7)$ & $28.4(34.3)$ & $36.0(35.1)$ \\
\hline $40-49$ & $18.5(47.0)$ & $18.3(43.2)$ & $20.1(42.1)$ & $17.5(43.8)$ \\
\hline \multicolumn{5}{|l|}{ Education level } \\
\hline No education & $28.2(42.6)$ & $21.2(42.2)$ & $19.1(36.5)$ & $26.4(40.1)$ \\
\hline Primary education & $20.0(44.0)$ & $20.1(45.6)$ & $17.8(38.0)$ & $19.7(41.9)$ \\
\hline Secondary/higher & $51.8(33.4)$ & $58.7(35.6)$ & $63.1(32.4)$ & $53.9(33.5)$ \\
\hline \multicolumn{5}{|l|}{ Religious affiliation } \\
\hline Christianity & $97.0(37.6)$ & $77.5(40.1)$ & $80.1(34.1)$ & $83.3(36.6)$ \\
\hline Islam & $2.7(54.0)$ & $15.0(37.8)$ & $15.2(35.1)$ & $12.0(37.4)$ \\
\hline Traditional & $0.1(99.5)$ & $4.2(38.8)$ & $2.0(35.9)$ & $2.3(37.5)$ \\
\hline Other & $0.2(0.5)$ & $3.334 .3)$ & $2.7(37.3)$ & $2.4(36.0)$ \\
\hline \multicolumn{5}{|l|}{ Ethnicity } \\
\hline Akan & $53.3(36.5)$ & $53.2(40.9)$ & $52.4(32.6)$ & $51.5(35.8)$ \\
\hline Ga-Dangme & $8.2(45.0)$ & $7.0(36.6)$ & $7.7(39.1)$ & $7.2(40.4)$ \\
\hline Ewe & $13.1(43.7)$ & $12.9(37.7)$ & $13.5(39.5)$ & $13.5(40.2)$ \\
\hline Mole-Dagbani & $12.8(36.0)$ & $16.1(36.6)$ & $14.8(35.5)$ & $15.6(36.0)$ \\
\hline Other & $12.6(40.8)$ & $10.8(40.8)$ & $11.6(31.1)$ & $12.2(36.7)$ \\
\hline \multicolumn{5}{|l|}{ Wealth status } \\
\hline Poor & $33.7(44.3)$ & $34.3(44.4)$ & $33.5(37.2)$ & $36.9(41.2)$ \\
\hline Middle & $18.8(41.7)$ & $19.9(43.7)$ & $20.6(36.3)$ & $19.8(39.6)$ \\
\hline Rich & $47.5(32.0)$ & $45.8(33.2)$ & $45.9(31.3)$ & $43.3(31.9)$ \\
\hline \multicolumn{5}{|l|}{ Marital status } \\
\hline Never married & $28.4(25.3)$ & $32.4(27.8)$ & $32.9(29.6)$ & $12.0(28.3)$ \\
\hline Married/living together & $62.4(40.4)$ & $58.5(41.5)$ & $56.6(36.3)$ & $84.2(38.8)$ \\
\hline Widowed/divorced/separated & $9.2(26.8)$ & $9.1(23.4)$ & $10.5(17.2)$ & $3.8(20.6)$ \\
\hline \multicolumn{5}{|l|}{ Work status } \\
\hline Working & $75.2(38.6)$ & $75.3(38.9)$ & 73.5 (33.5) & $83.1(36.4)$ \\
\hline Not working & $24.8(38.7)$ & $24.7(43.5)$ & $26.5(37.8)$ & $16.9(39.2)$ \\
\hline \multicolumn{5}{|l|}{ Parity } \\
\hline 0 & $31.6(27.4)$ & $33.7(25.8)$ & $31.3(22.1)$ & $15.2(24.5)$ \\
\hline $1-2$ & $26.0(36.3)$ & $27.0(37.5)$ & $28.2(31.0)$ & $33.0(34.1)$ \\
\hline $3-4$ & $20.1(40.0)$ & $20.8(43.0)$ & $21.5(35.0)$ & $27.5(38.3)$ \\
\hline $5+$ & $22.3(46.2)$ & $18.5(47.2)$ & $19.0(46.7)$ & $24.3(46.7)$ \\
\hline \multicolumn{5}{|l|}{ Residence } \\
\hline Urban & $48.4(32.5)$ & $48.5(35.6)$ & $53.8(33.4)$ & $46.6(33.7)$ \\
\hline Rural & $51.6(43.0)$ & $51.5(42.5)$ & $46.2(35.4)$ & $53.4(39.7)$ \\
\hline Total & 100 (38.6) & $100(39.5)$ & $100(34.4)$ & 100 (36.9) \\
\hline
\end{tabular}

Note: Prevalence of unmet need for family planning in parenthesis

the time of the surveys. About a third of the respondents had 1-2 (33.0\%) children and more than a fifth had 5 or more children (24.3\%) whereas $15.2 \%$ had no children. Lastly, more than half of the respondents were living in rural settings (53.4\%). 
The average unmet need for family planning was $36.9 \%$, albeit there were fluctuations over the study period. Unmet need was higher among respondents aged 15-19 (44.7\%) and $40-49(43.8 \%)$, as well as women with primary school education (41.9\%) and those without formal education (40.1\%). While the prevalence of unmet need was similar among the various religious denominations, it was higher among Ga-Dangme (40.4\%) and Ewe (40.2\%) respondents as well as those in poor households (41.2\%). The married or in-union (38.8\%), unemployed (39.2\%), highest parity (46.7\%), and rural (39.7\%) respondents all had a higher prevalence of unmet need for family planning than their counterparts.

\section{Spatial and temporal variations in unmet need for family planning}

To provide a broad description of the regions in the country, Table 2 was included. It contains selected aggregate-level socioeconomic characteristics for each region based on the study data such as percent of women educated, poor, unemployed, and using modern contraception among others. Using the proportion of the educated, poverty, and rurality as indicators of development in each region and modern contraceptive use as a reflection of attitude toward reproductive health $(\mathrm{RH})$, we describe three main categories of regions in the country. The proportion of unemployed women and main religion do not vary considerably by region while the main ethnicity of a region may not be a clear indication of development or positive attitude to RH.

On the one hand, Greater Accra, which hosts the national capital is the most developed region with the highest proportion of women with at least primary education (89.5\%), least poverty (3.6\%) and rurality (11.2\%), and a more positive attitude toward RH (29.6\%). Ashanti is a special region. The Ashanti region is somewhat similar to the Greater Accra region in development with a large proportion of educated women

Table 2: Selected socioeconomic characteristics of the regions

\begin{tabular}{|c|c|c|c|c|c|c|c|}
\hline Region & $\begin{array}{l}\% \\
\text { Educated }\end{array}$ & $\begin{array}{l}\% \\
\text { Poverty }\end{array}$ & $\begin{array}{l}\% \\
\text { Unemployed }\end{array}$ & $\begin{array}{l}\% \\
\text { Rural }\end{array}$ & $\begin{array}{l}\text { \% Modern } \\
\text { contraceptive } \\
\text { use }\end{array}$ & $\begin{array}{l}\text { \% Main } \\
\text { religion }\end{array}$ & $\%$ Main ethnicity \\
\hline Western & 81.1 & 30.9 & 15.6 & 62.6 & 28.0 & $\begin{array}{l}\text { Christianity } \\
(91.7)\end{array}$ & Akan (80.7) \\
\hline Central & 80.8 & 31.2 & 15.6 & 66.8 & 29.8 & $\begin{array}{l}\text { Christianity } \\
\text { (91.4) }\end{array}$ & Akan (87.8) \\
\hline $\begin{array}{l}\text { Greater } \\
\text { Accra }\end{array}$ & 89.5 & 3.6 & 19.3 & 11.2 & 29.6 & $\begin{array}{l}\text { Christianity } \\
(89.5)\end{array}$ & Akan (41.1) \\
\hline Volta & 77.5 & 48.6 & 15.8 & 70.1 & 30.9 & $\begin{array}{l}\text { Christianity } \\
(85.4)\end{array}$ & Ewe (80.6) \\
\hline Eastern & 86.0 & 39.0 & 19.6 & 62.0 & 29.2 & $\begin{array}{l}\text { Christianity } \\
\text { (93.5) }\end{array}$ & Akan (56.6) \\
\hline Ashanti & 86.3 & 23.0 & 16.2 & 44.0 & 25.6 & $\begin{array}{l}\text { Christianity } \\
\text { (89.1) }\end{array}$ & Akan (79.0) \\
\hline $\begin{array}{l}\text { Brong } \\
\text { Ahafo }\end{array}$ & 72.9 & 47.6 & 16.3 & 56.8 & 31.1 & $\begin{array}{l}\text { Christianity } \\
\text { (84.8) }\end{array}$ & Akan (66.3) \\
\hline Northern & 21.3 & 77.8 & 16.5 & 74.9 & 10.6 & $\begin{array}{l}\text { Christianity } \\
(45.6)\end{array}$ & $\begin{array}{l}\text { Mole-Dagbani } \\
\text { (54.3) }\end{array}$ \\
\hline Upper East & 42.4 & 80.9 & 13.5 & 80.0 & 25.1 & $\begin{array}{l}\text { Christianity } \\
(66.4)\end{array}$ & $\begin{array}{l}\text { Mole-Dagbani } \\
(76.6)\end{array}$ \\
\hline $\begin{array}{l}\text { Upper } \\
\text { West }\end{array}$ & 32.7 & 73.9 & 18.8 & 80.7 & 20.8 & $\begin{array}{l}\text { Christianity } \\
(61.6)\end{array}$ & $\begin{array}{l}\text { Mole-Dagbani } \\
\text { (57.5) }\end{array}$ \\
\hline
\end{tabular}

Source: GDHS 2003-2014 
(86.3\%), and similar modern contraceptive use (25.6\%). However, it has a considerably larger proportion of poor women (23.0\%) and rural areas (44.0\%). On the other hand, the Northern Region is the least developed in the country, with the poorest female education $(21.3 \%)$, higher poverty $(77.8 \%)$ and predominantly rural $(74.9 \%)$ as well as the lowest modern contraceptive use in the country (10.6\%). Two other regions, the Upper East and Upper West, that are not as extreme as the Northern Region are also mainly rural, with a high poverty level, relatively low women's education, but with a higher proportion of women using contraception. The remaining 5 regions look moderate and fall in-between the two categories of these 5 aforementioned regions.

The spatial and temporal patterns of unmet need for family planning have been pictorially presented in Figs. 1 and 2. In Fig. 1, the maps show that there were wide regional disparities in unmet need for family planning for 2003, 2008, and 2014. In 2003, the Central region, the Eastern region, the Volta Region, and the Upper East region had the highest unmet need for family planning between 42 and 55\% whereas the Upper West region had the lowest unmet need $(<33 \%)$. The Western region, Central region, and the Eastern region also had the highest unmet need for family planning (42-55\%) in 2008, whereas the Greater Accra and the Upper East region had the lowest unmet need $(<33 \%)$. In 2014, however, the Eastern region had the highest rate of unmet need for family planning, followed by the Ashanti Region and the Volta region whereas regions such as the Western, Brong Ahafo, Upper East, and the Upper West had the lowest unmet need for family planning $(<33 \%)$. In the same year, sexually active women in the Ashanti Region and the Volta region had between 37 and $42 \%$ unmet need for family planning.

Furthermore, Fig. 2 was produced in order to describe the trends in the total changes in the unmet need for family planning between 2003 and 2014 by region. Overall, there is a great variation in the time trends across the regions, suggesting inequality in the rates of change in unmet need within the country over time. The diagram shows that the Central region had the steepest improvement in unmet need for family planning, with a considerable reduction from about $55 \%$ to about $37 \%$ over the study period. The Upper West, Western, the Brong Ahafo as well as the Volta and the Northern region also had considerable improvements in unmet need for family planning over the study period. Conversely, the Ashanti region appeared to have worsening terms regarding the unmet need for family planning during this period, while the Eastern region, the Upper East region, and the Greater Accra region, had a fairly stable unmet need for family planning for over the study period.

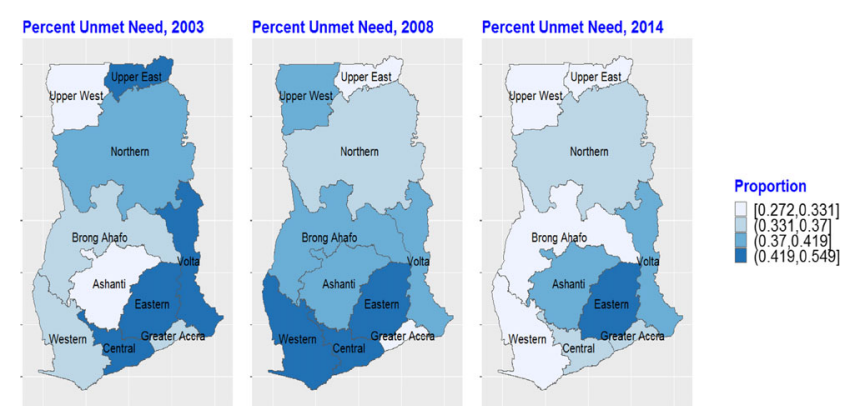

Fig. 1 Spatial variations in unmet need for family planning in Ghana: 2003-2014 


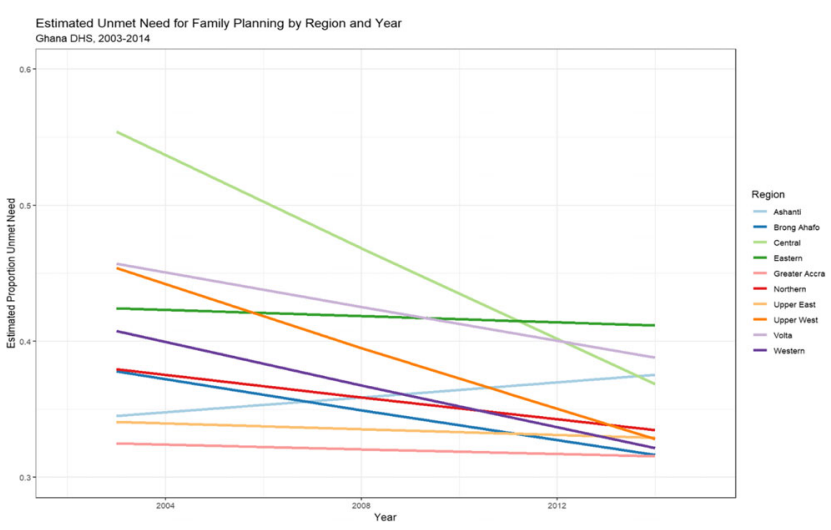

Fig. 2 Trends in the prevalence of unmet need for family planning in Ghana: 2003-2014

\section{Multilevel analysis results}

In this section, multilevel logistic regression analysis was performed to examine the effect of socioeconomic characteristics on unmet need for family planning in the country (Table 3). The results show that socioeconomic factors such as education level, wealth, marital, and work status had a significant association with unmet need for family planning even after controlling for demographic characteristics and time. Educational attainment was associated with unmet need for family planning with women who had secondary school or higher education having at least $12 \%$ lower odds of unmet need compared to their counterparts who had no formal education (model 2). Women from rich households also had at least $24 \%$ lower odds of unmet need for family planning compared to women from poor households, when all the factors were taken into consideration (model 3). With regard to marital status, married or cohabiting women had at least $18 \%$ higher odds of unmet need for family planning whereas widowed, divorced, or separated women had 55\% lower odds compared to never-married women when demographic characteristics are considered (model 3). Also, unemployed women had $25 \%$ higher odds of having an unmet need for family planning compared to their employed counterparts (model 3).

Demographic factors such as age, ethnicity, and parity were also significantly associated with unmet need for family planning. The age of a woman was found to be consistently associated with unmet need for family planning in both models 1 and 2 . Women aged $20-29(\mathrm{OR}=0.45), 30-39(\mathrm{OR}=0.32)$, and 40-49(OR =0.39) all had considerably lower odds of unmet need for family planning compared to women aged 15-19. However, in both models, religious affiliation and type of residence of a woman had no association with the pattern of unmet need for family planning. The ethnic background of a woman, however, was significantly associated with the unmet need for family planning. The GaDangme $(\mathrm{OR}=1.30)$ and Ewe $(\mathrm{OR}=1.17)$ women both had higher odds of unmet need for family planning whereas Mole-Dagbani $(\mathrm{OR}=0.85)$ women had lower odds compared to Akan women (model 3). The number of children ever born (parity) was also found to be associated with unmet need for family planning. Women who had 1-2 children (OR = 1.99), 3-4 children ( $\mathrm{OR}=2.73)$, and 5 or more $(\mathrm{OR}=3.94)$ children had considerably higher odds of unmet need for family planning compared to women who had no children (model 3). The results also show some temporal association, where women had 17\% reduced odds of unmet need for family planning in 2014 compared to 2003. 
Table 3 Multilevel logistic regression models of unmet need among women in Ghana

\begin{tabular}{|c|c|c|c|}
\hline Variables & Model 1 & Model 2 & Model 3 \\
\hline Education level ref $=$ no education) & $\mathrm{OR}(95 \% \mathrm{Cl})$ & $\mathrm{OR}(95 \% \mathrm{Cl})$ & $\mathrm{OR}(95 \% \mathrm{Cl})$ \\
\hline Primary education & $1.02(0.91,1.14)$ & $1.01(0.90,1.14)$ & $1.03(0.91,1.15)$ \\
\hline Secondary/higher & $0.80(0.72,0.89)^{*}$ & $0.88(0.79,0.99)^{*}$ & $0.92(0.81,1.03)$ \\
\hline \multicolumn{4}{|l|}{ Wealth status (ref $=$ poor) } \\
\hline Middle & $0.95(0.85,1.06)$ & $0.99(0.89,1.12)$ & $0.98(0.87,1.10)$ \\
\hline Rich & $0.68(0.62,0.76)^{*}$ & $0.79(0.69,0.90)^{*}$ & $0.76(0.66,0.87)^{*}$ \\
\hline \multicolumn{4}{|l|}{ Marital status (ref $=$ never married) } \\
\hline Married/living together & $1.55(1.35,1.77)^{*}$ & $1.18(1.00,1.41)^{*}$ & $1.14(0.96,1.37)$ \\
\hline Widowed/divorced/separated & $0.59(0.45,0.78)^{*}$ & $0.45(0.34,0.61)^{*}$ & $0.45(0.33,0.61)^{*}$ \\
\hline \multicolumn{4}{|l|}{ Work status (ref $=$ working) } \\
\hline Not working & $1.23(1.11,1.37)^{*}$ & $1.22(1.09,1.35)^{*}$ & $1.25(1.12,1.39)^{*}$ \\
\hline \multicolumn{4}{|l|}{ Age $(r e f=15-19)$} \\
\hline $20-29$ & & $0.44(0.37,0.52)^{*}$ & $0.45(0.38,0.54)^{*}$ \\
\hline $30-39$ & & $0.31(0.25,0.38)^{*}$ & $0.32(0.26,0.40)^{*}$ \\
\hline $40-49$ & & $0.37(0.30,0.47)^{*}$ & $0.39(0.31,0.49)^{*}$ \\
\hline \multicolumn{4}{|l|}{ Religious affiliation (ref = Christianity) } \\
\hline Islam & & $1.01(0.89,1.14)$ & $1.04(0.91,1.18)$ \\
\hline Traditional & & $0.94(0.74,1.18)$ & $0.93(0.73,1.18)$ \\
\hline Other & & $0.82(0.64,1.04)$ & $0.83(0.65,1.06)$ \\
\hline \multicolumn{4}{|l|}{ Ethnicity (ref = Akan) } \\
\hline Ga-Dangme & & $1.30(1.09,1.55)^{*}$ & $1.30(1.09,1.55)^{*}$ \\
\hline Ewe & & $1.18(1.01,1.36)^{*}$ & $1.17(1.01,1.36)^{*}$ \\
\hline Mole-Dagbani & & $0.83(0.71,0.96)^{*}$ & $0.85(0.73,0.98)^{*}$ \\
\hline Other & & $0.89(0.77,1.03)$ & $0.91(0.79,1.06)$ \\
\hline \multicolumn{4}{|l|}{ Parity $($ ref $=0)$} \\
\hline $1-2$ & & $1.95(1.65,2.30)^{*}$ & $1.99(1.68,2.35)^{*}$ \\
\hline $3-4$ & & $2.68(2.23,3.22)^{*}$ & $2.73(2.27,3.30)^{*}$ \\
\hline $5+$ & & $3.87(3.16,4.75)^{*}$ & $3.94(3.22,4.84)^{*}$ \\
\hline \multicolumn{4}{|l|}{ Type of residence (ref = urban) } \\
\hline Rural & & $0.94(0.84,1.05)$ & $0.91(0.81,1.01)$ \\
\hline \multicolumn{4}{|l|}{ Year $(r e f=2003)$} \\
\hline 2008 & & & $1.10(0.97,1.20)$ \\
\hline 2014 & & & $0.82(0.74,0.90)^{*}$ \\
\hline Variance for region & $0.05(0.02,0.15)$ & $0.014(0.01,0.06)$ & $0.02(0.01,0.07)$ \\
\hline ICC & 0.015 & 0.004 & 0.006 \\
\hline WAIC & 15737.10 & 15482.93 & 15448.81 \\
\hline Log-likelihood & -7923.04 & -7862.13 & -7856.64 \\
\hline
\end{tabular}

Note: $\mathrm{OR}=$ odds ratios, $\mathrm{Cl}=$ confidence intervals, $\mathrm{Ref}=$ reference category, $I C C=$ intraclass correlation coefficient, Significance $={ }^{*}<0.05$

\section{Discussion}

This paper seeks to describe the regional and temporal patterns in unmet need for family planning among women in Ghana from 2003 to 2014. The graphics in the study indicate that there are considerable regional disparities in unmet need for family planning in the country ranging between 27 and 55\% among the regions over the 
period. These fall just within the $20-58 \%$ range of unmet need for family planning documented in the literature (Wulifan, Brenner, Jahn, \& De Allegri, 2016). The findings show that the patterns of unmet need for family planning in Ghana are diverse and inconsistent over the study period. In effect, the findings provide evidence of three main trends of change in unmet need for family planning among the regions over the study period-decreasing trend, increasing trend, and a fairly stable trend. The steady improvement in unmet needs in some regions such as Central, Western, Upper West, Brong Ahafo, Northern, and Volta over the study period may be partly due to considerable improvements in modern contraceptive use in these regions within the period. In this regard, it could mean that Ghana's FP2020 agenda commitments may be yielding better results in these regions than in the Ashanti region in particular where the unmet need seems to be worsening. Similar outcomes have been also observed in Ghana from 1988 to 1998 (Govindasamy \& Boadi, 2000), and in Kenya from 1993 to 2003 (Ojakaa, 2008). This is an indication that no consistent improvement has been achieved in the country with regard to reducing the unmet need for family planning over the past three decades. This, it has been observed, may not only be the result of lack of access to contraceptive methods but also due to an increase in attitudinal resistance to contraceptive methods mainly because of previous experience of side effects (Ajong et al., 2016; Machiyama \& Cleland, 2014).

The study further finds that some socioeconomic, as well as demographic factors, are significantly associated with the variations in unmet need for family planning in the country. Women with formal education have a considerably higher unmet need for family planning than their counterparts with secondary or higher education, which provides support for our hypothesis. Consequently, secondary school or higher education is a protective factor against the unmet need for family planning (Alaba, Olaomi, \& Olubusoye, 2015; Nzokirishaka \& Itua, 2018). Predictably, household wealth is found to be strongly associated with unmet need for family planning and women from poor households are considerably disadvantaged concerning the unmet need for family planning than those from rich households. This strongly supports our hypothesis, and it is expected because this category of women has no economic power to access and patronize family planning services, unlike their rich counterparts. In consistent with the findings of this study, the role of household wealth status in unmet need for family planning has also been well-documented in the extant literature (Alaba et al., 2015; Ayele, Tesfaye, Gebreyes, \& Gebreselassie, 2013; Nzokirishaka \& Itua, 2018). Furthermore, marital status has some association with unmet need for family planning as women who were widowed, divorced or separated are considerably advantaged than married women and women who were never married. Never-married women are, therefore, disadvantaged providing support for the study hypothesis. Evidence of the marital status and unmet need for family planning nexus has been also established in the literature albeit married women have been observed to rather have a higher risk of having unmet need for family planning (Nyauchi \& Omedi, 2014). The lower risk of unmet need among the formerly married women can possibly be attributed to the belief that they have infrequent sexual intercourse (Machiyama \& Cleland, 2013), or abstain from sexual intercourse because they have no marital partner.

Additionally, this study shows that unemployed women have a substantially higher unmet need for family planning compared with employed women in Ghana, providing 
supporting evidence for the study hypothesis. This is consistent with findings of some extant studies which observed that women who are not working are significantly more likely to have an unmet need for family planning than employed women (Nyauchi \& Omedi, 2014; Oginni, Ahonsi, \& Adebajo, 2015; Ojakaa, 2008). Consequently, it can clearly be understood that the disparity in unmet need between the employed and the unemployed women may be mainly due to economic empowerment and affordability of family planning services.

Some demographic factors have also been found to have significantly affected unmet need for family planning over the period. It was found that age has a negative association with unmet needs. However, this association is rather curvilinear as the risk of unmet need for family planning becomes lowest in the middle age (30-39) but eventually wanes after age 40 . It is, therefore, apparent that teenage women in Ghana are greatly disadvantaged in terms of unmet need for family planning. This echoes the findings of some previous studies in other developing countries (Ayele et al., 2013; Oginni et al., 2015; Wulifan et al., 2016). In this context, the highest risk that is observed among the teenage women may probably be due to the cost and lack of access as many women in this age category are likely to be economically inactive and for this reason, they may not be able to afford the family planning services, unlike the older women. There is also evidence of marked ethnic background disparities in the risk of unmet need for family planning with Ga-Dangme and Ewe women having a higher risk of unmet need whereas Mole-Dagbani women have a lower risk of unmet need than their Akan counterparts. Analogously, considerable ethnic disparities in unmet need for family planning have been observed elsewhere in Nigeria (Alaba et al., 2015). It is, therefore, unclear why this may be the case. However, this may reflect the high prevalence of unmet needs in the Eastern region and the Volta region as shown in the descriptive findings and may well be due to inequalities in the provision of family planning services or interventions.

The number of children ever born to a woman is also found by some previous studies to have a significant effect on the state of her unmet need for family planning (Ayele et al., 2013; Oginni et al., 2015). This study finds a positive relationship between the parity of a woman and the unmet need for family planning. Thus, the risk of unmet need linearly increases with the increase in parity of a woman (Letamo \& Navaneetham, 2015; Wulifan et al., 2016). This clearly implies that women may be rather having a higher number of children simply because they are experiencing a higher risk of unmet need for family planning services, but not merely because they already have high parity. The study also shows some evidence of temporal improvement in the risk of unmet need for family planning in Ghana over the study period (2003-2014). Thus, the risk of unmet need for family planning significantly reduced among Ghanaian women in 2014 compared to 2003. The effect of time (survey year) on unmet need for family planning has been shown elsewhere in Ethiopia (Ayele et al., 2013), even though unlike the case of Ghana, the risk of unmet need has consistently reduced over time.

\section{Conclusions}

This study provides evidence of considerable regional disparities in unmet need for family planning among women in Ghana over time. The disparities follow diverse and inconsistent patterns over the study period which accentuate the inadequacies in family 
planning policies in Ghana for the past few decades. These patterns are considerably associated with socioeconomic characteristics such as educational attainment, household wealth, marital, and employment status of a woman in Ghana. Demographic factors such as age, ethnicity, and parity, as well as time (survey year), also play a prominent role in the patterns of unmet need for family planning in Ghana. In this study, the formally uneducated, the women from poor households, both the married and never-married women, and unemployed women all have a substantial disadvantage in the risk of unmet need for family planning in Ghana. This also applies to younger women (ages 15-19), Ga-Dangme and Ewe women, and higher parity women. Based on these, there is the need to formulate consistently effective family planning policies focusing mainly on the higher risk groups identified in this study. The inconsistency and diversity of the trends in unmet need further call for constant, effective, and equitable monitoring and evaluation as well as adequate funding for family planning programs in Ghana. Accessibility to family planning services should also be facilitated by extending services to women in deprived regions in the country. All these should be strongly incorporated in Ghana's FP2020 agenda and beyond.

\section{Abbreviations}

GDHS: Ghana Demographic and Health Survey; GHS: Ghana Health Service; GNFPP: Ghana National Family Planning Program; INLA: Integrated Nested Laplace Approximations

\section{Acknowledgements}

Data for this paper were obtained from the DHS Program.

\section{Authors' contributions}

SHN conceived and designed the study. SHN performed the analysis with technical support from CSS and FB. SHN led the initial draft of the manuscript with technical support from CSS and FB. All authors were involved in critically reviewing the intellectual content of the manuscript. All authors read and approved the final version of the manuscripts.

Funding

No specific funding has been provided for this study.

Availability of data and materials

The datasets used and/or analyzed during the current study are available at the DHS Program repository.

Competing interests

The authors declare that they have no competing interests.

Received: 15 June 2019 Accepted: 15 October 2019

Published online: 21 November 2019

References

Ajong, A. B., Njotang, P. N., Yakum, M. N., Essi, M. J., Essiben, F., Eko, F. E., et al. (2016). Determinants of unmet need for family planning among women in Urban Cameroon : a cross sectional survey in the Biyem-Assi Health District, Yaoundé. BMC Women's Health, 16(1), 4 https://doi.org/10.1186/s12905-016-0283-9.

Alaba, O. O., Olaomi, J., \& Olubusoye, O. E. (2015). Spatial pattern and determinants of unmet need of family planning in Nigeria. South African Family Practice, 57(5), 306-312 https://doi.org/10.1080/20786190.2015.1071536.

Ayele, W., Tesfaye, H., Gebreyes, R., \& Gebreselassie, T. (2013). Trends and determinants of unmet need for family planning and programme options, Ethiopia. Further Analysis of the 2000, 2005, and 2011 Demographic and Health Surveys. Calverton, MD: ICF International.

Bradley, S. E. K., Croft, T. N., Fishel, J. D., \& Westoff, C. F. (2012). Revising unmet need for family planning. DHS Analytical Studies No. 25. Calverton, Maryland, USA: ICF International.

R Core Team. (2018). R: A language and environment for statistical computing. R Foundation for Statistical Computing, Vienna, Austria. Retrieved from http://www.r-project.org/

Ghana Health Service (GHS), \& UNFPA. (2015). Day of dialogue on family planning in Ghana. Accra: GHS; UNFPA.

Ghana Statistical Service (GSS), Ghana Health Service (GHS), \& ICF International. (2015). Ghana Demographic and Health Survey 2014. Rockville,MD, USA: GSS, GHS, and ICF International.

Ghana Statistical Service (GSS), Ghana Health Service (GHS), \& ICF Macro. (2009). Ghana Demographic and Health Survey 2008. Accra, Ghana: GSS, GHS, and ICF Macro.

Ghana Statistical Service (GSS), Noguchi Memorial Institute for Medical Research (NMIMR), \& ORC Macro. (2004). Ghana demographic and health survey 2003. Calverton, Maryland: GSS, NMIMR, and ORC Macro. 
Government of Ghana. (1969). Population planning for national progress and prosperity: Ghana Population Policy. Accra: Ghana Publishing Corporation.

Government of Ghana. (1994). National population policy (Revised edition, 1994). Accra: National Population Council. Government of Ghana. (2015). Ghana family planning costed implementation plan 2016-2020. Accra: Ghana Health Service. Govindasamy, P., \& Boadi, E. (2000). A decade of unmet need for contraception in Ghana: programmatic and policy implications. Calverton, MD: Macro International Inc. and National Population Council Secretariat [Ghana].

Guttmacher Institute. (2016). Reasons for unmet need for contraception in Developing Countries. New York: Guttmacher Institute. Letamo, G., \& Navaneetham, K. (2015). Levels, trends and reasons for unmet need for family planning among married women in Botswana : a cross-sectional study. BMJ Open, 5, e006603. https://doi.org/10.1136/bmjopen-2014-006603

Machiyama, K. \& Cleland, J. (2013). Insights into unmet need in Ghana. London: London School of Hygiene \& Tropical Medicine.

Machiyama, K., \& Cleland, J. (2014). Unmet need for family planning in Ghana : the Shifting contributions of lack of access and attitudinal resistance. Studies in Family Planning, 45(2), 203-226.

Nyauchi, B., \& Omedi, G. (2014). Determinants of unmet need for family planning among women in Rural Kenya. African Population Studies, 28(2), 999-1008.

Nzokirishaka, A., \& Itua, I. (2018). Determinants of unmet need for family planning among married women of reproductive age in Burundi : a cross-sectional study. Contraception and Reproductive Medicine, 3, 11.

Oginni, A. B., Ahonsi, B. A., \& Adebajo, S. (2015). Trend and determinants of unmet need for family planning services among currently married women and sexually active unmarried women Aged 15-49 in Nigeria ( 2003 - 2013). African Population Studies, 29(1), 1483-1499.

Ojakaa, D. (2008). Trends and determinants of unmet need for family planning in Kenya. Calverton, MD: Macro International Inc..

Rue, H., Martino, S., \& Chopin, N. (2009). Approximate Bayesian inference for latent Gaussian models by using integrated nested Laplace approximations. Journal of the Royal Statistical Society, Series B, 71, 319-392.

Sedgh, G., Ashford, L. S., \& Hussain, R. (2016). Unmet need for contraception in developing countries : examining women's reasons for not using a method. New York: Guttmacher Institute.

UNFPA, \& PATH. (2008). Reducing unmet need for family planning: evidence- based strategies and approaches. Outlook, 25(1), 1-8. United Nations. (2015). Trends in contraceptive use worldwide 2015. New York: United Nations.

Upadhyay, U. D., \& Robey, B. (1999). Why family planning matters. Baltimore: John Hopkins University School of Public Health, Population Information Program.

WHO.(2019). Sexual and reproductive health: Unmet need for family planning. Retrieved from https://www.who.int/ reproductivehealth/topics/family_planning/unmet_need_fp/en/

Wulifan, J. K., Brenner, S., Jahn, A., \& De Allegri, M. (2016). A scoping review on determinants of unmet need for family planning among women of reproductive age in low and middle income countries. BMC Women's Health, 2(1), 2 https:// doi.org/10.1186/s12905-015-0281-3

Publisher's Note

Springer Nature remains neutral with regard to jurisdictional claims in published maps and institutional affiliations.

\section{Submit your manuscript to a SpringerOpen ${ }^{\circ}$ journal and benefit from:}

- Convenient online submission

- Rigorous peer review

- Open access: articles freely available online

High visibility within the field

Retaining the copyright to your article

Submit your next manuscript at $\boldsymbol{\nabla}$ springeropen.com 